\title{
Insilico Molecular Docking of Some Isolated Selected Compounds of Phoenix Sylvestris (L.) Against Diabetes
}

\author{
Joydip Barua, Muazzem Ahmad Sany, Largess Barua, Mohammad Hossen, Najia Absar, \\ Zamil Hossain, Hajera Begum, SahidaAkther, Nasrin Akter and Shermin Akther* \\ Department of Pharmacy, Bangladesh
}

*Corresponding author: Shermin Akther, Department of Pharmacy, BGC Trust University Bangladesh

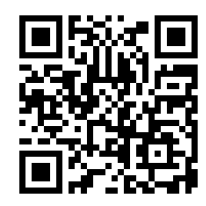

\section{ARTICLE INFO}

Received: 慧 March 06, 2019

Published: 慧 March 20, 2019

Citation: Joydip B, M Ahmad Sany, Largess B, M Hossen, S Akther, et al., Insilico Molecular Docking of Some Isolated Selected Compounds of Phoenix Sylvestris (L.) Against Diabetes. Biomed J Sci \& Tech Res 16(2)-2019. BJSTR. MS.ID.002819.

Keywords: Phoenix sylvestris (L.); Alpha-amylase; Molecular docking; 4-methylcatechol
ABSTRACT

Phoenix sylvestris is a very graceful palm which is also known as Wild date palm, Silver date palm, date sugar palm and belongs to the family Arecaceae. The various parts of plant reported possessing diuretic, analgesic effect, anti-inflammatory, antibacterial and neuropharmacological activities. Phoenix sylvestris is traditionally claimed to have antidiabetic, antidiarrheal, anti-dysentery activity and used in the treatment of a toothache, menstrual complaint. Our aim of the study to performed molecular docking studies to identify potential binding affinities of the phytocompounds from Phoenix sylvestris, namely 4-methylcatechol towards $\alpha$-amylase for searching of the lead molecule against diabetes. A wide range of docking score found during molecular docking by Schrodinger. 2, 3-Dihydro-3,5-dihydroxy-6-methyl-4H-pyran-4-one and 4-methylcatechol showed the docking score respectively $-5.044 \mathrm{~kJ} / \mathrm{mol}$ and $-5.303 \mathrm{~kJ} / \mathrm{mol}$ against $\alpha$-amylase. Between all the compounds 4-methylcatechol showed the best docking score towards $\alpha$-amylase. So, 4-methylcatechol is the best compound for $\alpha$-amylase enzyme inhibition, as it possessed the best value in Molecular Docking. Further, in vivo investigation needs to identify $\alpha$-amylase enzyme inhibitory activity of isolated compounds from Phoenix sylvestris.

\section{Introduction}

The term Diabetes mellitus (DM) is a metabolic disorder of multiple etiology characterized by abnormal fat, carbohydrate and protein metabolism resulting from defects in insulin secretion, insulin action, or both. [1,2] It is one of the most challenging heterogeneous diseases, can be simply classified into type 1 diabetes mellitus and type 2 diabetes mellitus. [3,4] Historically, the excellence between type 1 diabetes mellitus and type 2 diabetes mellitus has largely depended on the clinical presentation, such as age at disease onset, the presence of ketosis and also the dependence on insulin secretion. Type1 diabetes mellitus, appearing mainly in childhood or young adulthood, is characterized by T cells-mediated autoimmune destruction of the pancreatic islet b-cells, rendering the pancreas unable to synthesize and secrete insulin. [5] Type 2 diabetes mellitus, mainly appearing in adulthood, is the result of insulin resistance and relative insulin deficiency. Patients with type 2 diabetes mellitus have a higher risk of cancer involving the breast, endometrium, stomach, colorectum, liver, pancreas, urinary bladder, and lymphoid tissue. [6,7] The mechanisms of increased cancer risk of diabetic patients may be related to insulin resistance, hyperinsulinemia, proinflammatory status and increased oxidative stress $[4,8]$.

Diabetes is a common disease. The current worldwide prevalence is assessed to be approximately $250 \times 106$, and it is expected to reach $380 \times 106$ by 2025 . In recent years, the prevalence of diabetes is increasing in Bangladesh in both urban and rural areas [9]. A recent study reported that majority adults with type 2 diabetes in Bangladesh have uncontrolled diabetes with a high prevalence of hazard factors crediting to early advancement of inconveniences [10]. One such enzyme, human pancreatic $\alpha$-amylase (HPA, $\alpha 1$,4glucan-4-glucanohydrolase, E.C. 3.2.1.1) plays a vital role in DM. It catalyzes the initial step in the hydrolysis of starch to maltose which is eventually degraded to glucose by $\alpha$-glucosidases. Hence, retardation of starch digestion by HPA inhibition plays a key role in the control of postprandial hyperglycemia in type II DM [11]. By inhibiting HPA in the small intestines, the rate of hydrolysis of starch is decreased delaying the digestion process. This spreading 
of the digestion process reduces the amount of glucose generated and released in the blood and is one of the effective strategies for lowering post prandial hyperglycemia [12].

The use herbal medicine is gaining support and recognition across the world because most of these products are believed to have bioactive compounds responsible for healing various diseases without any side effects and at a lower cost. Phoenix Sylvestris is a very graceful palm which is also known as Wild date palm, Silver date palm, date sugar palm and belongs to the family Arecaceae. Phoenix Sylvestris is a very graceful palm which is also known as Wild date palm, Silver date palm, date sugar palm and belongs to the family Arecaceae. In Bangladesh, is known as Khejur. It is a palm tree cultivated for its syrupy juice and edible fruit in Bangladesh. [13] In Bangladesh, Khejur palm is produced as a homestead crop; however, it grows naturally or is cultivated in fallow lands, around homesteads, farmland boundary and even in the marginal lands along the roads and canals [14]. Fruits of the plant are used to treat back pain, stomachache, toothache, headache, arthritis, pain of buttocks, fever, piles, nervous debility, and as nervine tonic, restorative, sedative in ethnomedicine $[13,15]$.

The sap of Khejur palm is a good source of vitamins of the B group and contains, in addition, a variable amount of ascorbic acid, [16] freshly harvested sap consists of sucrose around 10\%, minimal invert sugar of $<0.5 \%$ and a small amount of protein, gums, and minerals. Phoenix Sylvestris leaves are traditionally claimed to have antidiabetic, antidiarrheal, anti-dysentery activity and used in the treatment of a toothache, menstrual complaint $[17,18]$. Computational simulations of drug-target interactions using in silico molecular docking and molecular dynamics approaches are commonly used for the rational design and screening of drugs [19]. Molecular docking has become a major computational method for the prediction of ligand-receptor interactions [20]. A productive docking strategy must have the ability to adequately envision the local ligand represent the receptor limiting site (i.e.to find the trial ligand geometry inside a particular resistance confine and the related physical-compound sub molecular affiliations [21-24]. The aim of the study to find the mechanism of action of the isolated compounds from Phoenix Sylvestris was explored the anti-diabetic activity by molecular docking analysis.

\section{Materials and Methods}

\section{In silico Molecular Docking Protein Preparation}

The 3D coordinates of the crystal structure of alpha-amylase (PDB:1PPI) were downloaded from the RCSB protein data bank (http://www.rcsb.org/pdb) [25]. It is a worldwide repository of information about the 3D structure of biological molecules, including proteins and nucleic acids. Then water molecules were removed from the protein PDB: 1PPI. The protein structure was corrected by the utilization of alternate conformation. The resultant protein file was subjected to energy minimization by force field. After the energy minimization, the protein file was subjected to define and edit binding site option available on the tools panel to explore the plausible binding site within the protein (1PPI). Using force field OPLS_2005, minimization was carried out setting maximum heavy atom RMSD (root-mean-square-deviation) to $0.30 \AA ̊$.

\section{Ligand Preparation}

The structures of six major representative compounds i.e., Diethylnitrosamine (CID: 5921), 2, 3-Dihydro-3,5-dihydroxy6-methyl-4H-pyran-4-one (CID: 119838), 4-methylcatechol (CID: 9958), 2,4-Di-tert-butyl phenol (CID: 7311), and Diethyl Phthalate (CID: 6781) were obtained from PubChem database. The ligands were prepared with LigPrep tool embedded in Maestro 2015, neutralized at pH 7.0 \pm 2.0 using Epik and minimized by force field OPLS_2005.

\section{Receptor Grid Generation}

Receptor grids were calculated for prepared proteins such that various ligand poses bind within the predicted active site during docking. In Glide, grids were generated keeping the default parameters of van der Waals scaling factor 1.00 and charge cutoff 0.25 subjected to OPLS 2005 force field. A cubic box of specific dimensions centered around the centroid of the active site residues (Reference ligand active site) was generated for the receptor. The bounding box was set to $14 \AA \times 14 \AA \times 14 \AA$ for docking experiments.

\section{Glide Standard Precision (SP) Ligand Docking}

SP flexible ligand docking was carried out in Glide of Schrödinger-Maestro v 10.1 [26]. within which penalties were applied to non-cis/trans amide bonds. Van der Waals scaling factor and partial charge cutoff were selected to be 0.80 and 0.15 , respectively for ligand atoms. Final scoring was performed on energy-minimized poses and displayed as Glide score. The bestdocked pose with lowest Glide score value was recorded for each ligand.

\section{Results \& Discussions}

\section{In Silico Molecular Docking Analysis}

In this study, the binding mode of the $\alpha$-amylase enzyme was investigated by doing computational analysis, glide docking. Both glide standard (SP) and extra precision (XP) mode had been introduced, where extra precision mode used for cross-validation purpose [27]. Grid-based docking study was used to analyze the binding modes of molecules with the amino acids present in the active pocket of the protein. To identify the potential antidiabetic lead molecule, we have subjected the docking analysis of the active compounds of Phoenix Sylvestris (L.) to the active site of BACE1. In order to study the interaction of the compounds with alphaamylase (PDB id: 1PPI). We performed Glide docking analysis by Schrodinger suite v10.1, where among of these compounds 4-methylcatechol shows highest docking score against both of the enzymes. Docking Score suggested that 4-methylcatechol had the highest affinity to the alpha-amylase corresponding to the other compound. The results of docking analysis were described in Table 1 and the docking figure showed in Figure 1. 


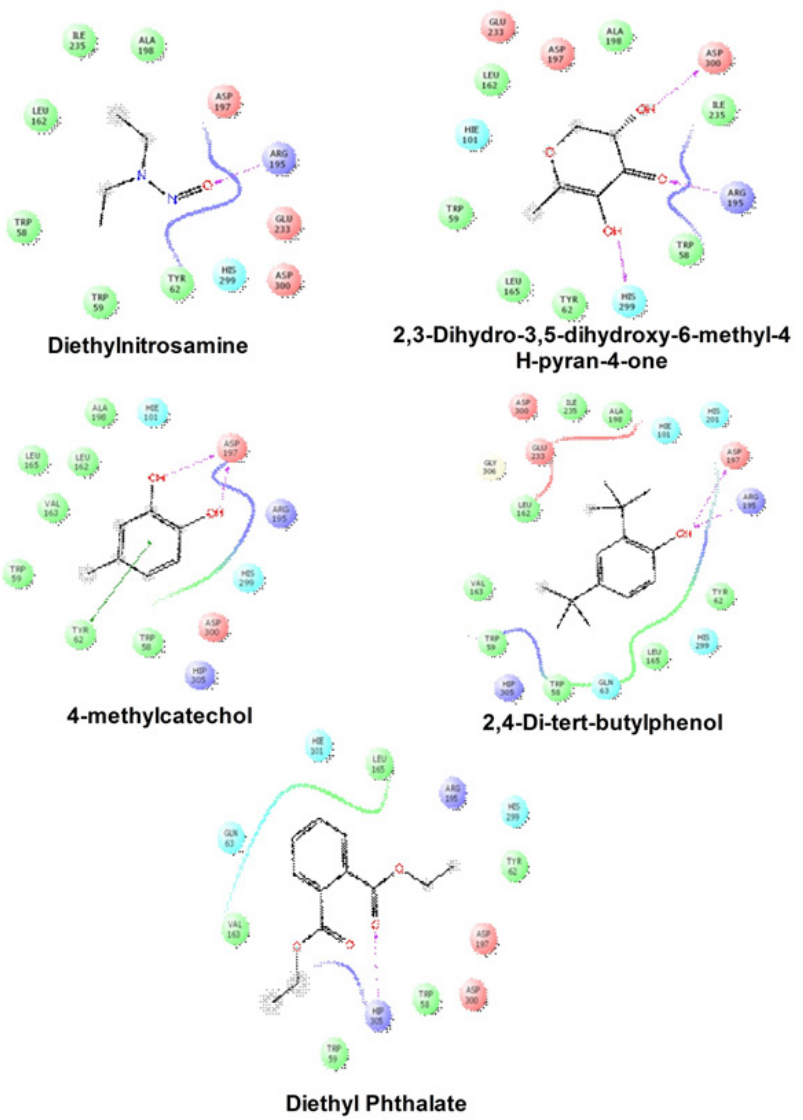

Figure 1: Schematic representation of the interactions between the best pose found of the selected compounds with alphaamylase (PDB ID: 1PPI).

Table 1: Docking results of compounds diethyl nitrosamine (CID 5921), 2,3-dihydro-3,5-dihydroxy-6-methyl-4H-pyran-4-one (CID 119838), 4-methylcatechol (CID 9958), 2,4-di-tert-butylphenol (CID 7311) and diethyl phthalate (CID 6781) with alpha-amylase (PDB id: 1PPI).

\begin{tabular}{|c|c|c|c|}
\hline Compound Name & Compound Id & Docking Score & -3.571 \\
\hline Diethyl nitrosamine & 5921 & -5.044 & -15.042 \\
\hline $\begin{array}{c}\text { 2, 3-Dihydro-3,5-dihydroxy-6- } \\
\text { methyl-4H-pyran-4-one }\end{array}$ & 119838 & -5.303 & -27.276 \\
\hline 4-methylcatechol & 9958 & -25.993 & -26.658 \\
\hline 2,4-Di-tert-butylphenol & 7311 & -4.62 \\
\hline Diethyl Phthalate & 6781 & -30.352 \\
\hline
\end{tabular}

Figure 1. Schematic representation of the interactions between the best pose found of the selected compounds with alpha-amylase (PDB ID: 1PPI). The colors indicate the residue (or species) type: Red-acidic (Asp, Glu), Green-hydrophobic (Ala, Val,Ile, Leu, Tyr, Phe, Trp, Met, Cys, Pro), Purple-basic (Hip, Lys, Arg), Blue-polar (Ser, Thr, Gln, Asn, His, Hie, Hid), Light gray-other (Gly, water), and Darker gray-metal atoms. Interactions with the protein are marked with lines between ligand atoms and protein residues: Solid pink- $\mathrm{H}-$ bonds to the protein backbone, Dotted pink-H-bonds to protein side chains, Green-pi-pi stacking interactions, Orange-pi-cation interactions. Ligand atoms that are exposed to solvent are marked with gray spheres. The protein "pocket" is displayed with a line around the ligand, colored with the color of the nearest protein residue. The gap in the line shows the opening of the pocket.

\section{Conclusion}

From the study, it was found that Phoenix Sylvestris (L.) could be a great source of new alpha-amylase activity. Insilco model support that all the isolated compound from P. sylvestris might be an alphaamylase inhibitor. Further in vivo investigation needs to identify the potential inhibitory activity of isolated compounds from $\mathrm{P}$. sylvestris.

\section{Acknowledgment}

The authors thankful Mr. Arkajyoti Paul for providing the software and helping in manuscript writing.

\section{References}

1. Orbak R, Simsek S, Orbak Z, Kavrut F, Colak M, et al. (2008) The influence of type-1 diabetes mellitus on dentition and oral health in children and adolescents. Yonsei Med J 49(3): 357-365. 
2. Latti BR, Kalburge J V, Birajdar SB, Latti RG (2018) Evaluation of the relationship between dental caries, diabetes mellitus and oral microbiota in diabetics. J Oral Maxillofac Pathol JOMFP 22(2): 282.

3. Tuomi T, Santoro N, Caprio S, Cai M, Weng J, et al. (2014) The many faces of diabetes: a disease with increasing heterogeneity. Lancet 383(9922): 1084-1094.

4. Yi B, Huang G, Zhou Z (2016) Different role of zinc transporter 8 between type 1 diabetes mellitus and type 2 diabetes mellitus. J Diabetes Investig 7(4): 459-465.

5. Castano L, Eisenbarth GS (1990) Type-I diabetes: a chronic autoimmune disease of human mouse and rat. Annu Rev Immunol 8(1): 647-679.

6. Tseng CH (2012) Pioglitazone and bladder cancer: a population-based study of Taiwanese. Diabetes Care 35(2): 278-280.

7. Arcidiacono B, Iiritano S, Nocera A, Possidente K, Nevolo MT, et al. (2012) Insulin resistance and cancer risk: an overview of the pathogenetic mechanisms. Exp Diabetes Res 789174.

8. Tseng CH (2015) Type 2 diabetes mellitus and kidney cancer risk: a retrospective cohort analysis of the National Health Insurance. PLoS One 10(11): e0142480.

9. Biswas T, Islam A, Rawal LB, Islam SMS (2016) The increasing prevalence of diabetes in Bangladesh: a scoping review. Public Health 138: 4-11.

10. Islam SMS, Alam DS, Wahiduzzaman M, Louis W Niessend, GuenterFroeschl et al. (2015) Clinical characteristics and complications of patients with type 2 diabetes attending an urban hospital in Bangladesh. Diabetes Metab Syndr Clin Res Rev 9(1): 7-13.

11. Tarling CA, Woods K, Zhang R (2008) The search for novel human pancreatic $\alpha$-amylase inhibitors: high-throughput screening of terrestrial and marine natural product extracts. ChemBioChem 9(3): 433-438.

12. Ponnusamy S, Haldar S, Mulani F, Zinjarde S, Thulasiram H, et al. (2015) Gedunin and Azadiradione: human pancreatic alpha-amylase inhibiting limonoids from neem (Azadirachta indica) as anti-diabetic agents. PLoS One 10(10): e0140113.

13. Ghani A (1998) Medicinal Plants of Bangladesh: Chemical Constituents and Uses. Asiatic society of Bangladesh Pp: 467.

14. Arntzen CJ (1994) Encyclopedia of Agricultural Science. RITTER ELLEN M.

ISSN: 2574-1241

DOI: 10.26717/BJSTR.2019.16.002819

Shermin Akther. Biomed J Sci \& Tech Res

(C) This work is licensed under Creative

Submission Link: https://biomedres.us/submit-manuscript.php
15. Acharya E, Pokhrel B (2006) Ethno-medicinal plants used by Bantar of Bhaudaha Morang Nepal. Our Nat 4(1): 96-103.

16. HALIM MDA, Chowdhury MSH, Muhammed N, Rahman M, Koike M, et al. (2008) Sap production from khejur palm (phoenix sylvestris roxb) husbandry: a substantial means of seasonal livelihood in rural Bangladesh. For Trees Livelihoods 18(3): 305-318.

17. Jha KK, Khosa RL (2011) Cressa Cretica Linn: An Important Medicinal Plant-A Review on Its Traditional UsesPhytochemical and Pharmacological Properties. Sangeeta Rani Sudhir Chaudhary Pradeep Singh Garima Mishra.

18. Sharma DC (2012) Biochemical Analysis and Molecular Characterization of wild India Date Palm Phoenix Sylvestris L Roxb.

19. Jorgensen WL (2004) The many roles of computation in drug discovery. Science (80-) 303(5665): 1813-1818.

20. Kellenberger E, Rodrigo J, Muller P, Rognan D, (2004) Comparative evaluation of eight docking tools for docking and virtual screening accuracy. Proteins Struct Funct Bioinforma 57(2): 225-242.

21. Arun Y, Saranraj K, Balachandran C, Perumal PT (2014) Novel spirooxindole-pyrrolidine compounds: Synthesis, anticancer and molecular docking studies. Eur J Med Chem 74: 50-64

22. Lu SH, Wu JW, Liu HL, Zhao JH, Liu KT, et al. (2011) The discovery of potential acetylcholinesterase inhibitors: a combination of pharmacophore modeling, virtual screening, and molecular docking studies. J Biomed Sci 18(1): 8.

23. Shoichet BK, McGovern SL, Wei B, Irwin JJ (2002) Lead discovery using molecular docking. Curr Opin Chem Biol 6(4): 439-446.

24. Oshiro C, Bradley EK, Eksterowicz J, Evensen E, Lamb ML, et al. (2004) Performance of 3D-database molecular docking studies into homology models. J Med Chem 47(3): 764-767.

25. Berman HM, Westbrook J, Feng Z, Gilliland G, Bhat TN, et al. (2000) The protein data bank. Nucleic Acids Res 28(1): 235-242.

26. Venkatachalam CM, Jiang X, Oldfield T, Waldman M (2003) LigandFit: a novel method for the shape-directed rapid docking of ligands to protein active sites. J Mol Graph Model 21(4): 289-307.

27. Veeramachaneni GK, Raj KK, Chalasani LM, Annamraju SK, JS B, et al. (2015) Shape based virtual screening and molecular docking towards designing novel pancreatic lipase inhibitors. Bioinformation 11(12): 535-542.

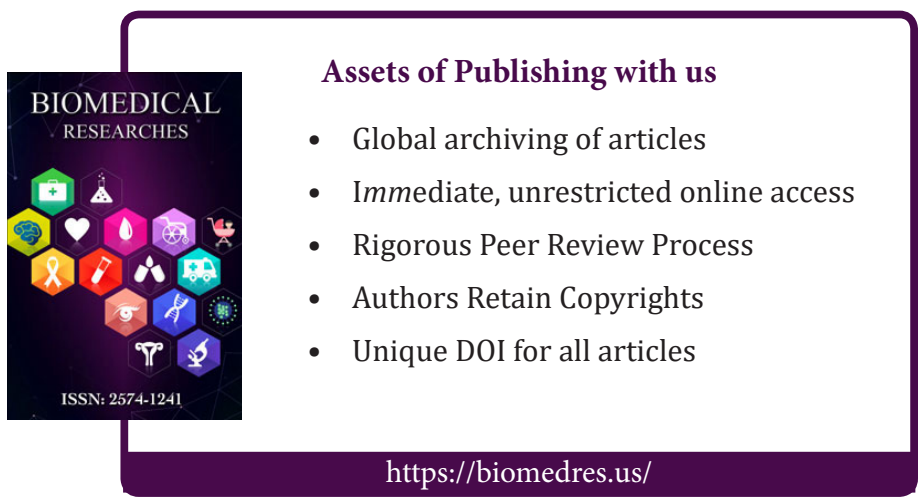

